\title{
Chronic constipation: Current treatment options
}

\author{
Louis Wing Cheong Liu MD MEng PhD FRCPC
}

LWC Liu. Chronic constipation: Current treatment options. Can J Gastroenterol 2011;25(Suppl B):22B-28B.

Chronic constipation is a common functional gastrointestinal disorder that affects patients of all ages. In 2007, a consensus group of 10 Canadian gastroenterologists developed a set of recommendations pertaining to the management of chronic constipation and constipationdominant irritable bowel syndrome. Since then, tegaserod has been withdrawn from the Canadian market. A new, highly selective serotonin receptor subtype 4 agonist, prucalopride, has been examined in several large, randomized, placebo-controlled trials demonstrating its efficacy and safety in the management of patients with chronic constipation. Additional studies evaluating the use of stimulant laxatives, polyethylene glycol and probiotics in the management of chronic constipation have also been published. The present review summarizes the previous recommendations and new evidence supporting different treatment modalities - namely, diet and lifestyle, bulking agents, stool softeners, osmotic and stimulant laxatives, prucalopride and probiotics in the management of chronic constipation. A brief summary of lubiprostone and linaclotide is also presented. The quality of evidence is presented by adopting the Grading of Recommendations, Assessment, Development and Evaluation system. Finally, a management pyramid for patients with chronic constipation is proposed based on the quality of evidence, impact of each modality on constipation and on general health, and their availabilities in Canada.

Key Words: Biofeedback; Chronic constipation; Dyssynergic defecation; Laxative; Prucalopride

Oreral hronic constipation has been reported in $15 \%$ to $25 \%$ of the general population (1-3). It affects patients of all ages and both sexes, and different cultures and ethnicities. It is more commonly reported in women, elderly patients, residents of chronic care facilities and patients with concurrent psychiatric illnesses. Constipation decreases patients' quality of life (QoL); its impact on $\mathrm{QoL}$ is comparable with patients suffering from asthma, rheumatoid arthritis and psoriatic arthritis (4).

The Rome III diagnostic criteria identify patients with functional constipation when $25 \%$ of bowel movements are associated with at least two of the following symptoms: straining; hard or lumpy stools; a sense of incomplete evacuation; a sense of anorectal obstruction; the need for manual manoeuvres; or fewer than three defecations per week in the previous three months with an onset of symptoms longer than six months (5). In addition, these patients should also rarely complain of loose stool without the use of a laxative and do not meet the diagnostic criteria for irritable bowel syndrome (IBS). Recurrent abdominal pain or discomfort is the hallmark difference that distinguishes patients with functional chronic constipation from constipationdominant IBS (IBS-C).

Chronic constipation can be subclassified into four categories: normal transit, slow transit, dyssynergic defecation (DD) and slow transit-dyssynergic combination $(6,7)$. The Rome III criteria clearly reflect the fact that patients with chronic constipation who seek medical attention due to dissatisfaction with their bowel function can have normal bowel movement frequency. Not too surprisingly, approximately $50 \%$ of constipated patients are found to have normal-transit

\author{
La constipation chronique : les possibilités \\ thérapeutiques actuelles
}

La constipation chronique est un trouble gastro-intestinal fonctionnel commun qui touche des patients de tout âge. En 2007, un groupe consensuel de dix gastroentérologues canadiens a élaboré une série de recommandations portant sur la prise en charge de la constipation chronique et du syndrome du côlon irritable dominé par la constipation. Depuis, le tégasérod a été retiré du marché canadien. Le prucalopride, un nouvel agoniste hautement sélectif des récepteurs de la sérotonine de sous-type 4, a fait l'objet de plusieurs grands essais aléatoires et contrôlés contre placebo qui en démontrent l'efficacité et l'innocuité dans la prise en charge des patients atteints de constipation chronique. D'autres études publiées portent également sur l'utilisation des laxatifs stimulants, du polyéthylène glycol et des probiotiques dans la prise en charge de la constipation chronique. La présente analyse contient le résumé des recommandations antérieures et des nouvelles données probantes étayant diverses modalités thérapeutiques, notamment le régime et le mode de vie, les agents gonflants, les laxatifs émollients, les osmotiques et les laxatifs stimulants, le prucalopride et les probiotiques dans la prise en charge de la constipation. Un court résumé de la lubiprostone et du linaclotide est également présenté. La qualité des données probantes est présentée conformément au système de qualité, d'élaboration et d'évaluation des recommandations. Enfin, une pyramide de prise en charge des patients atteints de constipation chronique est présentée d'après la qualité des données probantes, les effets de chaque modalité sur la constipation et sur la santé générale ainsi que sur leur disponibilité au Canada.

constipation (1). Slow-transit constipation accounts for $13 \%$ to $15 \%$ of chronically constipated patients, whereas DD can be found in $25 \%$ to $30 \%$ of patients (6). Combined slow-transit dyssynergic constipation has been reported in $10 \%$ to $15 \%$ of patients with chronic constipation. In patients with dyssynergic defecation, up to $50 \%$ are found to have concurrent slow-transit constipation. In some of these patients, the transit abnormality can be normalized after the DD is resolved.

In 2007, a group of 10 Canadian gastroenterologists conducted a systematic review of the literature and developed a set of consensus treatment recommendations for chronic constipation and IBS-C (6). More recently, in part driven by the development of new pharmacological agents, several review articles addressing the treatment of chronic constipation have been published in Europe (3) and the United States $(7,8)$. However, some of these pharmacological agents and investigational tools are not widely available in Canada. The present article reviews the evidence regarding the use of different therapeutic interventions in the treatment of primary chronic constipation and highlights the options that are available in Canada.

\section{IDENTIFYING PATIENTS WITH PRIMARY FUNCTIONAL CHRONIC CONSTIPATION}

A thorough and meticulous history is most helpful in ruling out constipation secondary to drugs (eg, opioids, calcium-channel blockers and anticholinergics) or other underlying medical illness (eg, connective-tissue, neurological or metabolic diseases). Patients with alarming symptoms, such as new onset of symptoms after 50 years of age, rectal

Division of Gastroenterology; Department of Medicine, University of Toronto, Toronto, Ontario

Correspondence and reprints: Dr Louis Wing Cheong Liu, University of Toronto, Toronto Western Hospital, University Health Network, 399 Bathurst

Street, Main Pavillion, 8th Floor, Room 329, Toronto, Ontario M5T 2S8. Telephone 416-603-5276, fax 416-603-6204, e-mail louis.liu@uhn.on.ca Received and accepted for publication June 13, 2011 
bleeding, nocturnal symptoms, significant weight loss, fever, anemia or abnormal physical examination, warrant further investigations to rule out secondary causes (6). The Bristol stool chart is easy to use and validated to correlate stool consistency with colonic transit time (9). Stool type 1 or 2 indicates slow-transit constipation. The importance of a comprehensive pelvic floor and anorectal digital examination has been emphasized by several experts, with the goal of evaluating the presence of pelvic floor dyssynergy $(7,8)$. The Rome III diagnostic criteria define functional defecation disorders in a subset of patients with functional constipation entirely based on anorectal manometry (ARM) or imaging studies, namely, having two of the following criteria: impaired evacuation based on a failed balloon expulsion test or imaging, inappropriate contraction of the pelvic floor muscles (ie, anal sphincter or puborectalis); less than $20 \%$ relaxation of basal resting sphincter pressure assessed by ARM, imaging or electromyography; or inadequate propulsive forces assessed by ARM or imaging (10). However, ARM, defecography and electromyography are not widely available in Canada. A careful digital rectal examination by an expert is reported to have a sensitivity of $75 \%$ and a specificity of $87 \%$ in identifying DD in patients with chronic constipation (11). The pelvic floor examination should start with a careful perianal examination for visible lesions, followed by assessing the perianal sensory and anocutaneous wink reflex of all four quadrants. The digital rectal examination enables the examiner to reveal the resting tone of the anal sphincter and, more importantly in the context of constipation, to evaluate whether there is an adequate elevation of intrarectal pressure associated with coordinated anal sphincter relaxation while the patient is asked to strain. At the same time, descending perineum syndrome is suspected in a female patient if the perineum reaches or descends below the ischial tuberosities during the Valsalva maneouvre.

\section{LIFESTYLE AND DIETARY MODIFICATION}

Although there are insufficient data to support the notion that diet and lifestyle modification can improve chronic constipation, it is widely accepted and recommended by experts as first-line therapy $(6,8,12)$.

\section{Constipation and immobility}

Studies supporting physical activity in the management of constipation are sparse and inconsistent. In healthy individuals, physical activity either prolongs $(13)$ or has no effect $(14,15)$ on bowel transit time. In a randomized control trial (RCT) (16), regular exercise did not significantly improve constipation symptoms or the need for regular laxative use in institutionalized, elderly patients (64 to 94 years of age $[n=157]$ ) over a six-month period. These participants engaged in moderately intense activity with a median duration of 32 min per day. A questionnaire study identified 140 of 1069 employees in a Veterans Administrative Database who met the Rome I criteria for constipation (17); self-reported physical activity was not related to the risk of constipation but was associated with improved QoL. A small uncontrolled study (18) reported that individualized multimodal conservative intervention comprised of advice on dietary supplementation, fluid intake, exercise, position to defecate, the gastrocolic reflex and over-thecounter laxative use improved $\mathrm{QoL}$ and decreased the severity of constipation in 27 patients. Although these studies did not consistently show that physical activity improved constipation, they suggest that physical activity improves QoL. A similar association has also been reported in patients with IBS-C. In a small 12-week study involving 56 patients who met the Rome II diagnostic criteria for IBS (19), exercise significantly improved constipation compared with the standard of care. A recent RCT (20) showed that an individualized, supervised physical activity program (20 min to $60 \mathrm{~min}$ of moderate-to-vigorous activity, three to five days per week) over a 12-week period significantly improved the symptom severity scores of IBS patients. These studies consistently illustrated that although physical activity may not improve stool frequency, it is recommended because it appears to improve $\mathrm{QoL}$ and decrease bowel symptom severity in addition to offering other general health benefits.

\section{Bulking agents: Fibre supplementation}

Bulking agents are organic polysaccharides that increase stool weight and improve stool consistency by retaining fluid in the stool. Evidence supporting the use of bulking agents in the management of chronic constipation has previously been summarized $(6,12)$. Psyllium is the most commonly used bulking agent in Canada. In placebo-control trials, psyllium has been shown to decrease stool transit time (21), and improve stool frequency, consistency and weight (22); when psyllium was compared with lactulose, the magnitude of effects on stool frequency was similar $(23,24)$. Although these were small studies with a short treatment duration (four weeks), and given the associated benefit of dietary fibre in reducing coronary heart disease (25) and lowering low-density lipoprotein cholesterol (26), it is generally recommended as the initial conservative treatment for chronic constipation.

\section{STOOL SOFTENERS}

Stool softeners are anionic surfactants with an emulsifying detergentlike property that increase the content of water in stool. Although stool softeners are commonly used in the treatment of constipation, evidence supporting their use is weak. A small RCT conducted in 1968 involving 15 elderly patients (27) suggested that sodium docusate increased stool frequency; however, its effect could not be reproduced in a later RCT using calcium docusate (28). Whether the lack of effect in the latter study was related to the use of a calcium instead of a sodium salt is debatable. In a more recent two-week, multicentre, double-blinded RCT involving 170 patients (29), sodium docusate was found to be less effective than psyllium at improving stool frequency.

\section{LAXATIVES}

\section{Osmotic laxatives}

Osmotic laxatives contain poorly absorbable substances that serve as osmotic agents to draw water into the intestinal lumen. The most commonly used osmotic laxatives in Canada are 'Milk of Magnesia' (Phillips, Bayer Inc, Canada) (magnesium hydroxide), lactulose and polyethylene glycol (PEG). Although there have been no RCTs demonstrating the efficacy of magnesium salts in the management of mild to moderate chronic constipation, expert opinions and clinical experiences support its use (6). Because magnesium is renally excreted, its use in patients with renal insufficiency is not recommended.

Lactulose was shown to be safe and effective in normalizing stool frequency. Three RCTs (two in patients with functional constipation [30,31], and one in patients with opiate-associated constipation [32]) showed that lactulose significantly improved stool frequency with a number needed to treat (NNT) of 3.9 (6).

PEG is a nonabsorbable and nonmetabolized polymer that draws fluid into the bowel lumen. Both electrolyte-enriched PEG (33-35) (commonly used to prepare patients for colonoscopy) and electrolytefree PEG (PEG 3350) (36,37) have been shown to be effective in improving stool frequency and consistency in RCTs. When PEG 3350 was compared with lactulose, PEG significantly improved constipation symptoms. Although both PEG 3350 and lactulose were similarly welltolerated, patients treated with PEG reported less flatus (38). In the United Kingdom, using the Health Improvement Network Database, PEG was shown to be more cost effective than lactulose in the treatment of chronic constipation (39). A recent meta-analysis, which included five placebo-controlled RCTs, demonstrated that the NNT to improve constipation using osmotic laxatives (lactulose was used in one study and PEG in four studies) was 3 (95\% CI 2 to 4) (40).

\section{Stimulant laxatives}

The commonly available stimulant laxatives in Canada are bisacodyl, senna, cascara and sodium picosulfate (SPS). Senna and cascara can frequently be found in herbal remedies or tea. The active ingredients of Cascara sagrada (Rhamnus purshiana, also known as sacred bark or California buckthorn) are hydroxyanthraquinone glycosides found in the dried bark of the plant. The fresh bark, however, causes nausea, vomiting and griping abdominal pain. Senna alexandrina has also 
TABLE 1

Summary of pivotal trials of prucalopride

\begin{tabular}{|c|c|c|c|c|c|c|c|}
\hline \multirow{2}{*}{$\begin{array}{l}\text { First author } \\
\text { (reference), year }\end{array}$} & \multirow{2}{*}{$\begin{array}{l}\text { Country, } \\
\text { number of sites, } n\end{array}$} & \multirow{2}{*}{$\begin{array}{l}\text { Patients, } n \\
\text { (\% female) }\end{array}$} & \multicolumn{3}{|c|}{ Achieved primary end point, \% } & \multicolumn{2}{|c|}{ Number needed to treat } \\
\hline & & & Placebo & $2 \mathrm{mg}$ & $4 \mathrm{mg}$ & $2 \mathrm{mg}$ & $4 \mathrm{mg}$ \\
\hline Camilleri (46), 2008 & United States, 38 & $620(87.9)$ & 12 & $30.9^{\star \star}$ & $28.4^{\star *}$ & 5.3 & 5.7 \\
\hline Quigley (47), 2009 & United States, 41 & $641(86.6)$ & 12.1 & $23.9^{*}$ & $23.9^{*}$ & 8.5 & 8.8 \\
\hline Tack (48), 2009 & International, 65 & $713(90.8)$ & 9.6 & $19.5^{*}$ & $23.6^{*}$ & 10.1 & 7.1 \\
\hline
\end{tabular}

All three trials were multicentre studies involving secondary and tertiary centres, for a study duration of 12 weeks. All studies enrolled patients who satisfied the modified Rome II criteria ( $\leq 2$ complete spontaneous bowel movements [CSBMs]/week for a minimum of six months, and at least one of the following symptoms for at least 25\% of stools: very hard (little balls) and/or hard stools, a sensation of incomplete evacuation, or straining during defecation). Primary end point was defined as at least three CSBMs per week. Dosage of prucalopride was $2 \mathrm{mg}$ or $4 \mathrm{mg}$ daily. The international study involved patients from Europe, Australia, Canada and South Africa (48). ${ }^{*} P<0.01$ versus placebo; ${ }^{* *} P<0.001$ versus placebo

been widely used for the treatment of constipation, even though there is no clinical controlled trial to support its use in the management of chronic constipation $(6,12)$. Senna can be found in several herbal remedies (eg, Black draught, Chatoliocon, Daffy's Exlixir, Diasenna, Swedish bitters and many diet teas). Due to the widespread use of senna in herbal remedies, Health Canada has issued a product monograph as a guide to industry for the preparation of product licence applications and labels for natural health product market authorization. Similar to cascara, the active ingredients found in senna plants are anthraquinone glycosides.

Bisacodyl is a phenolphthalein that is activated by the action of endogenous deacetylase enzymes found in the mucosa of the small intestine and colon, whereas SPS is converted by desulfatases of the colonic microflora. Bisacodyl and SPS are both prodrugs that are converted in the gut into the same active metabolite, bis-(phydroxyphenyl)-pyridyl-2-methane, which exhibits an antiabsorptivesecretory and prokinetic effect (41). In a recent meta-analysis including two RCTs (one from the United Kingdom using bisacodyl published in abstract form, and another from Germany using SPS) (40), the NNT to achieve at least three complete spontaneous bowel movements (CSBMs) per week was 3. Both were short-term studies (four weeks); hence, long-term safety and efficacy are unclear. In long-term use, dependency and cathartic colon are of concern, albeit not supported by well-documented evidence $(6,42)$. Stimulant laxatives tend to be recommended for occasional use.

\section{PROKINETIC AGENTS}

Cisapride and tegaserod were two previously widely used prokinetic agents in Canada. Their prokinetic properties mediate primarily through the agonistic effect of the seratonin subtype 4 (5-HT4) receptor. Cisapride was approved in 1980 for the treatment of chronic constipation. The United States Food and Drug Administration (FDA) issued a warning letter concerning its cardiotoxicity in July 2000. Cisapride was subsequently withdrawn from the market. In 2002, tegaserod was initially approved for short-term treatment in women with IBS-C. It was later approved for use in adults with chronic constipation in 2004. In March 2007, Novartis, as mandated by the FDA, reported a retrospective pool analysis of 29 clinical trials (11,614 patients treated with tegaserod and 7031 patients with placebo) that indicated an increased risk of cardiovascular events (angina, myocardial infarction and cerebral vascular accidents), with a number needed to harm of 1000 (the event rate was $0.11 \%$ in tegaserod-treated patients versus $0.01 \%$ in placebo-treated patients) (43). Although the cardiovascular event rate in tergaserod-treated patients was similar to the general population, Novartis voluntarily withdrew tegaserod from the market in March 2007. Using a health insurance database containing data of five million people from across the United States, a recent large cohort observation study (44) matched 52,229 patients who were initiated on tegaserod with 52,229 individuals with similar characteristics who were not. It showed no increase in cardiovascular ischemic events. Currently, tegaserod is not available in Canada, but it can be accessed under emergency situations as defined and approved by the FDA in the United States. In Canada, cisapride can be accessed with strict patient monitoring through the compassionate limited-access program of Health Canada.

\section{Prucalopride}

The cardiovascular toxicity of cisapride and tegaserod is related to their nonspecific effect on the delay rectifying potassium (HERG-K) channel that leads to prolong QT interval, precipitating torsade de pointes. Prucalopride is a new, highly selective $5 \mathrm{HT}_{4}$ receptor agonist with a binding affinity to $5 \mathrm{HT}_{4}$ receptors greater than 150 times the affinity to the HERG-K channel (45).

A meta-analysis of seven RCTs comparing prucalopride $(2 \mathrm{mg}$ or 4 mg orally daily) with placebo in 2639 patients with chronic constipation (40) reported an NNT of 6 . There was no significant heterogeneity among these trials. The treatment duration of the three pivotal trials (46-48 [Table 1]) was 12 weeks, and four weeks in the remaining four trials. The efficacy of prucalopride to help patients achieve at least three CSBMs was similar in the $2 \mathrm{mg}$ and $4 \mathrm{mg}$ groups. Headache, nausea and diarrhea, but not abdominal pain, were more common in the prucalopride-treated group, with a number needed to harm of 10. It is important to note that these side effects in the active treatment group frequently occurred within the first $24 \mathrm{~h}$, when the first CSBM was commonly reported after initiation of therapy. When the side effect profile was analyzed after the initial $24 \mathrm{~h}$, no significant increase in these side effects was detected in the prucalopride-treated group (49). In all three pivotal trials (46-48), and two recent four-week placebo-controlled studies involving elderly patients older than 65 years of age $(n=389)$ $(50,51)$, prucalopride was efficacious and safe without any significant effect on the QT interval or increase in cardiovascular events. Longterm efficacy and safety up to the 18-month follow-up has recently been reported (52).

In Canada, prucalopride is currently under review by Health Canada but has not been approved and is, therefore, not yet available in this country.

\section{OTHER AGENTS}

Lubiprostone is a bicyclic fatty acid derived from prostaglandin E1. It activates the apical membrane of the chloride channel in the intestinal epithelium that stimulates intestinal fluid secretion. Three RCTs, comparing lubiprostone ( $24 \mu$ g orally twice/day) with placebo in 610 chronically constipated patients over a treatment duration of four weeks, showed an overall NNT of 4. No significant heterogeneity was noted in these studies (40). Diarrhea and nausea were more frequently reported in the lubiprostone group; abdominal pain and headache were not different. Lubiprostone is not available in Canada.

Linaclotide is an oligopeptide that increases the intracellular levels of cyclic guanosine monophosphate of enterocytes by activation of guanylate cyclase-C, resulting in an increase in intraluminal chloride and bicarbonate secretion. One phase II trial of four weeks' treatment duration and two RCTs of 12 weeks' duration (published in abstract form) demonstrated that linaclotide improved stool consistency and frequency (12), and decreased abdominal bloating and discomfort (40). 
TABLE 2

Summary of probiotic trial characteristics in adult patients with chronic constipation

\begin{tabular}{|c|c|c|c|c|c|}
\hline $\begin{array}{l}\text { Author } \\
\text { (reference), year }\end{array}$ & Country & Probiotic & $\begin{array}{c}\text { Daily dosage } \\
\text { (colony-forming units) }\end{array}$ & $\mathbf{n}$ & Duration \\
\hline 2010 & \multirow{2}{*}{ Italy } & $\begin{array}{l}\text { Bifidobacterium breve (BR03) } \\
\text { versus }\end{array}$ & $2.5 \times 10^{9}$ & & \\
\hline & & $\begin{array}{l}\text { Bifidobacterium lactis (BS01) } \\
\text { versus }\end{array}$ & $5 \times 10^{9}$ & 110 & \\
\hline $\begin{array}{l}\text { Koebnick et al (56), } \\
2003\end{array}$ & Germany & Placebo & & 35 & \\
\hline \multirow[t]{2}{*}{$\begin{array}{l}\text { Mollenbrink and } \\
\text { Bruckschen (54), } 1994\end{array}$} & \multirow[t]{2}{*}{ Germany } & $\begin{array}{l}\text { Escherichia coli (Nissle 1917) } \\
\text { versus }\end{array}$ & $25 \times 10^{9}$ & 35 & 4/4 weeks* \\
\hline & & Placebo & & 35 & \\
\hline
\end{tabular}

All studies were double-blinded, placebo-controlled randomized controlled trials, except the Yang et al study (55), which was not blinded, and the Mollenbrink and Bruckschen (54) study, which was a crossover study. *One week run-in phase, followed by two four-week periods of crossover treatment phases without a washout period; during the treatment phase, patients received either placebo or E coli (Nissle 1917)

\section{PROBIOTICS}

Probiotics are live microorganisms that, when ingested in adequate amounts, confer a health benefit to the host. There is immense interest and demand from the public for probiotics. The global market for probiotics increased from $\$ 14.9$ billion in 2007 to $\$ 15.9$ billion by the end of 2008. It is speculated that the sales of probiotics will reach $\$ 19.6$ billion by 2013 . Over the past decade, there has been growing popularity in using probiotics for the management of chronic constipation. The most widely studied organisms are in the genera Bifidobacterium and Lactobacillus. Recently, a systematic review (53) was performed to evaluate the use of probiotics in adults and children for the treatment of functional constipation; five RCTs (three involving adults [54-56] and two involving children) were included in the analysis. It showed that probiotics statistically improved stool consistency and frequency. A more recent double-blinded, placebo-controlled RCT divided 300 chronically constipated patients (151 males and 149 females) into three groups (placebo, Lactobacillus plantarum LP01 and Bifidobacterium breve BR03, or Bifidobacterium lactis BS01) for a treatment duration of 30 days (57). The treatment groups significantly improved in all aspects of constipation symptoms. Symptom improvement was not significantly different between the two probiotic-treated groups. The authors concluded that both probiotic regimens were effective in the management of their patients. Although this was the largest study, it included patients with very mild constipation and did not use the Rome diagnostic criteria. The mean weekly stool frequencies at baseline were $5.61 \pm 2.24$ in the placebo group, and $5.30 \pm 2.24$ and $5.79 \pm 2.19$ in the two active treatment groups. The generalizability of this study to patients with chronic constipation is questionable. No adverse events were reported in these trials.

These studies examined different strains of probiotics used in different dosages (Table 2). Except for the most recent trial (57), there has been no direct comparison of different probiotic regimens. Currently, conclusions regarding the efficacy of a particular strain can only be made based on a single study with methodological limitations that investigated a small number of participants. Thus, it is unclear whether any one particular strain of probiotic is more effective than another. Due to the paucity and quality of the existing data, and until further evidence becomes available, the use of probiotics in the management of chronic constipation remains experimental.

\section{SURGICAL PROCEDURES}

Subtotal colectomy with ileorectal anastomosis has been the most adopted procedure performed in patients with severe slow-transit constipation refractory to medical therapies. Although studies with shortterm follow-up periods suggest that surgery appears to be effective in alleviating constipation symptoms, its popularity has been declining since the mid-1990s because of poor long-term functional outcomes (58). A study from a single tertiary centre in the United Kingdom (59) followed 44 women who had a median bowel frequency of once every four weeks before surgery. Over the 15-year follow-up period, 50\% of patients normalized their bowel frequency; however, $34 \%$ had diarrhea and $11 \%$ experienced persistent or recurrent constipation requiring the use of laxatives. Seventy per cent of patients continued to experience abdominal pain. Psychiatric treatment for severe psychological disorders was needed in $23 \%$ of patients. It is important to emphasize to patients that abdominal pain and bloating generally do not improve after surgery.

\section{A PROPOSED STRATEGY FOR THE MANAGEMENT OF CHRONIC CONSTIPATION}

Patients who present frequently to the gastroenterology clinic with chronic constipation have experienced constipation for years to decades. An investigative and attentive history that addresses patient's concerns and fears not only enables the physician to assess the secondary causes of constipation and evaluate alarming systems, but also serves as an initial step in establishing a therapeutic relationship. Although physicians commonly consider constipation as fewer than three bowel movements per week, patients more frequently complain of straining, bloating and a sense of incomplete evacuation (60). Target investigations that directly address patient fears and additional tests that were omitted from previous assessments are generally adequate to ameliorate patient concerns.

An important part of the history and physical examination is to evaluate whether the patient is experiencing DD. These patients generally complain of excess straining even when there is a strong urge for defecation, or even if the stool is soft (Bristol type 4 or higher). The need for digital manipulation to stimulate or facilitate stool evacuation is predictive of DD. A careful digital rectal examination is able to identify at least two-thirds of patients with DD. In patients with an indeterminant history or physical examination, ARM with the 


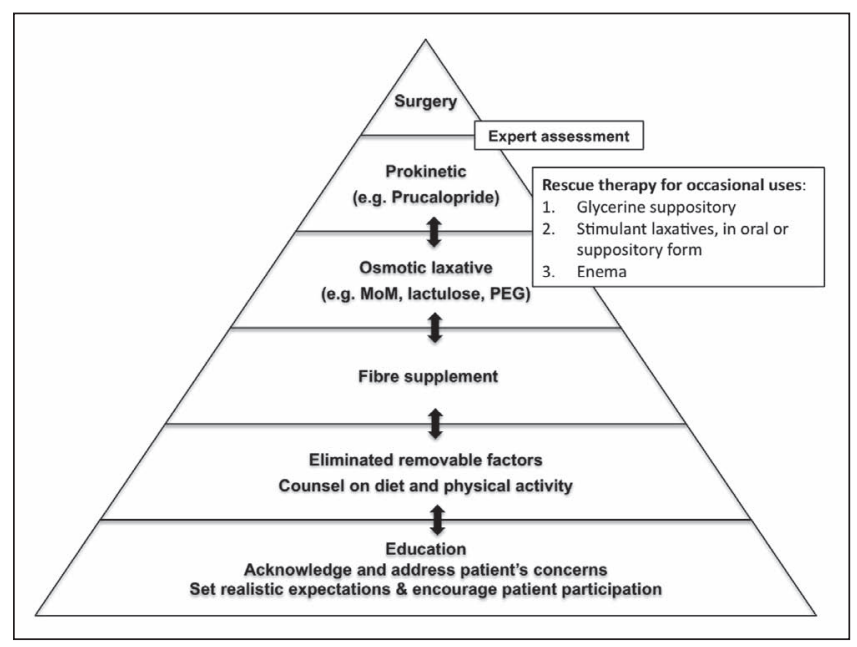

Figure 1) Management pyramid for patients with chronic constipation. The bidirectional arrows indicate that continuous modification of the treatment regimen is necessary depending on the patient's treatment response and tolerance to the therapy. The patient should be assessed in an expert centre when surgical management is being considered. MoM Milk of Magnesia (Phillips, Bayer Inc, Canada); PEG Polyethylene glycol

balloon expulsion test can be used to ascertain the diagnosis. Even when DD is suspected, a therapeutic trial of medical management is sensible when ARM is not easily accessible in the practice region. If the patient does not achieve the expected therapeutic response(s), a referral for expert assessment with ARM is recommended.

The main stage of therapy for DD is biofeedback. Biofeedback is an audio-visual training program that teaches a patient how to optimally use his or her abdominal and pelvic floor muscles to effectively perform the evacuation manoeuvre. It can also be used to optimize rectal sensitivity and provide targeted, objective guidance for patients to practice Kegel exercises to improve anal sphincter motor profile. Three RCTs (one comparing biofeedback with PEG [61]), one with sham biofeedback [62] and one with diazepam or placebo [63]) consistently showed that biofeedback improved constipation symptoms in patients with DD. The NNT to improve CSBM, straining and abdominal pain, and to decrease the need of rescue laxative use were 1.5 to 2.5 in all three trials. Up to $75 \%$ of patients with DD achieve satisfactory bowel functions after biofeedback in specialized centres. It is important to emphasize that a cognitive, motivated patient and a welltrained and experienced therapist are both instrumental in achieving the optimal therapeutic outcome.

Once the diagnosis of functional chronic constipation is established, the foundation of the management pyramid is patient education and setting realistic expectations (Figure 1). Actively engaging the patient to set sensible and achievable treatment goals will help to improve compliance and therapy success. It is unrealistic for a patient to expect complete normalization of stool frequency, or elimination of all bowel symptoms that he or she has been experiencing for years to decades after one visit. It is important to educate the patient about the natural variation of bowel functions and the range of normal stool frequency. Counselling on adequate dietary fibre (aiming to achieve $25 \mathrm{~g} /$ day to $35 \mathrm{~g} /$ day), fluid intake and physical activity are part of the initial conservative management. The patient must realize that fibre is fermented by intestinal bacteria, which produces gas. Rapid increase of fibre ingestion increases bloating, flatulence, abdominal discomfort and can worsen diarrhea or constipation. Gradual incremental increases of $3 \mathrm{~g} /$ week to $4 \mathrm{~g} /$ week minimizes these symptoms and improves compliance. Fibre supplementation can be added if necessary.

Although many of these conservative measures have probably previously been recommended to the patient, it is important to reiterate their importance so that the patient can take an active role in
TABLE 3

Quality of evidence supporting different treatments for chronic constipation

\begin{tabular}{lll}
\hline Treatment modality & $\begin{array}{l}\text { Quality } \\
\text { of evidence }\end{array}$ & $\begin{array}{l}\text { Recommended } \\
\text { dosage }\end{array}$ \\
\hline Physical activity & Low & - \\
Psyllium & Moderate & $6-12 \mathrm{~g}$ daily \\
Sodium ducosate & Low & $100-200 \mathrm{mg}$ twice daily \\
Lactulose & Moderate & $15-30 \mathrm{~mL}$ daily \\
PEG (electrolyte enriched) & High & $250-500 \mathrm{~mL}$ daily \\
PEG 3350 (electrolyte free) & High & $17 \mathrm{~g}$ daily \\
Senna* & Low & Vary \\
Bisacodyl/SPS* & Moderate & $10 \mathrm{mg}$ daily as needed \\
Probiotics & Low/very low & Vary \\
Prucalopride & High & 2 mg daily ${ }^{\dagger}$ \\
\hline
\end{tabular}

The quality of evidence was assessed according to the Grading of Recommendations, Assessment, Development and Evaluation (GRADE) system (64), which defines study quality as high (further research is very unlikely to change our confidence in the estimate of effect; moderate (further research is likely to have an important impact on our confidence in the estimate of effect and may change the estimate); low (further research is very likely to have an important impact on our confidence in the estimate of effect and is likely to change the estimate); or very low (any estimate of effect is very uncertain). The dosages of senna and probiotics depends on the preparation. *Senna, bisacodyl and sodium picosulfate (SPS) are recommended for occasional use. Long-term safety and efficacy of chronic use are unclear; ${ }^{\dagger}$ The recommended dosage is based on the dosages used in pivotal trials. Dose reduction is likely required in patients with severe renal insufficiency or hepatic impairment. PEG Polyethylene glycol

improving their bowel health and function. The quality of evidence supporting different treatment modalities in the management of chronic constipation is summarized in Table 3. The choice of osmotic laxatives is largely dependent on patient tolerance, financial situation and drug coverage. Lactulose is reimbursed by all provincial and private drug programs. Electrolyte-enriched formulas of PEG are covered by some plans. PEG 3350 (electrolyte free) is an over-the-counter medication and is generally not covered. PEG tends to cause less abdominal bloating and flatulence. In my practice, I find osmotic laxatives to be more effective if they are initiated after the colon has been cleansed by colonoscopy-type bowel preparations, particularly in patients with significant fecal loading. Glycerine suppositories frequently help to stimulate bowel movement and are considered to be safe for long-term use (6). They can be used every two to three days as necessary. Stimulant laxative and enema are generally recommended for occasional use as rescue therapy (6).

In view of the limitations of existing data and clinical experience in using probiotics in the management of chronic constipation, they cannot be recommended as a standard therapy in the management pyramid (Figure 1). However, probiotics appear to improve functional complaints and may be helpful in patients with mild symptoms. Additional studies to evaluate probiotic strains, dosage and the patient population that will ultimately benefit are required to recommend its use.

In the cisapride and tegaserod era, clinical experience demonstrated that these prokinetic agents are effective in the management of chronic constipation. Unfortunately, these agents are no longer available in Canada, although cisapride can be accessed by the limitedassessed program through Heath Canada. Prucalopride is a new, highly selective $5 \mathrm{HT}_{4}$ agonist and is currently under review by Health Canada. When it is approved, prucalopride will offer an effective and safe option for patients who are not satisfied with the other medical treatments in the management pyramid.

Although surgery is the final treatment option in the management pyramid of chronic constipation (Figure 1), it should be recommended 
with extreme caution because of the poor long-term functional outcomes. Surgical interventions should only be considered in highly selected, medically refractory patients after a thorough expert assessment.

CONFLICTS OF INTEREST: Dr Liu has received honoraria as a speaker and attending advisory board member from Nycomed and JanssenOrtho in the past 12 months.

\section{REFERENCES}

1. Higgins PD, Johanson JF. Epidemiology of constipation in North America: A systematic review. Am J Gastroenterol 2004;99:750-9.

2. Wald A, Scarpignato C, Mueller-Lissner S, et al. A multinational survey of prevalence and patterns of laxative use among adults with self-defined constipation. Aliment Pharmacol Ther 2008;28:917-30.

3. Tack J, Muller-Lissner S. Treatment of chronic constipation: Current pharmacologic approaches and future directions. Clin Gastroenterol Hepatol 2009;7:502-8; quiz 496.

4. Irvine EJ, Ferrazzi S, Pare P, Thompson WG, Rance L. Health-related quality of life in functional GI disorders: Focus on constipation and resource utilization. Am J Gastroenterol 2002;97:1986-3.

5. Longstreth GF, Thompson WG, Chey WD, Houghton LA, Mearin F, Spiller RC. Functional bowel disorders. Gastroenterology 2006;130:1480-91.

6. Pare P, Bridges R, Champion MC, et al. Recommendations on chronic constipation (including constipation associated with irritable bowel syndrome) treatment. Can J Gastroenterol 2007;21(Suppl B):3B-22B.

7. Singh S, Rao SS. Pharmacologic management of chronic constipation. Gastroenterol Clin North Am 2010;39:509-27.

8. Camilleri M, Bharucha AE. Behavioural and new pharmacological treatments for constipation: Getting the balance right. Gut 2010;59:1288-96.

9. Lewis SJ, Heaton KW. Stool form scale as a useful guide to intestinal transit time. Scand J Gastroenterol 1997;32:920-4.

10. Bharucha AE, Wald A, Enck P, Rao S. Functional anorectal disorders. Gastroenterology 2006;130:1510-8.

11. Tantiphlachiva K, Rao P, Attaluri A, Rao SS. Digital rectal examination is a useful tool for identifying patients with dyssynergia. Clin Gastroenterol Hepatol 2010;8:955-60.

12. Emmanuel AV, Tack J, Quigley EM, Talley NJ. Pharmacological management of constipation. Neurogastroenterol Motil 2009;21(Suppl 2):41-54.

13. Meshkinpour H, Kemp C, Fairshter R. Effect of aerobic exercise on mouth-to-cecum transit time. Gastroenterology 1989;96:938-41.

14. Soffer EE, Summers RW, Gisolfi C. Effect of exercise on intestinal motility and transit in trained athletes. Am J Physiol 1991;260:G698-702.

15. Coenen C, Wegener M, Wedmann B, Schmidt G, Hoffmann S. Does physical exercise influence bowel transit time in healthy young men? Am J Gastroenterol 1992;87:292-5.

16. Chin APMJ, van Poppel MN, van Mechelen W. Effects of resistance and functional-skills training on habitual activity and constipation among older adults living in long-term care facilities: A randomized controlled trial. BMC Geriatr 2006;6:9.

17. Tuteja AK, Talley NJ, Joos SK, Woehl JV, Hickam DH Is constipation associated with decreased physical activity in normally active subjects? Am J Gastroenterol 2005;100:124-9.

18. Ostaszkiewicz J, Hornby L, Millar L, Ockerby C. The effects of conservative treatment for constipation on symptom severity and quality of life in community-dwelling adults. J Wound Ostomy Continence Nurs 2010;37:193-8.

19. Daley AJ, Grimmett C, Roberts L, et al. The effects of exercise upon symptoms and quality of life in patients diagnosed with irritable bowel syndrome: A randomised controlled trial. Int J Sports Med 2008;29:778-82.

20. Johannesson E, Simren M, Strid H, Bajor A, Sadik R. Physical activity improves symptoms in irritable bowel syndrome: A randomized controlled trial. Am J Gastroenterol 2011;106:915-22.

21. Cheskin LJ, Kamal N, Crowell MD, Schuster MM, Whitehead WE. Mechanisms of constipation in older persons and effects of fiber compared with placebo. J Am Geriatr Soc 1995;43:666-9.
22. Ashraf W, Park F, Lof J, Quigley EM. Effects of psyllium therapy on stool characteristics, colon transit and anorectal function in chronic idiopathic constipation. Aliment Pharmacol Ther 1995;9:639-47.

23. Rouse M, Chapman N, Mahapatra M, Grillage M, Atkinson SN, Prescott P. An open, randomised, parallel group study of lactulose versus ispaghula in the treatment of chronic constipation in adults. Br J Clin Pract 1991;45:28-30.

24. Dettmar PW, Sykes J. A multi-centre, general practice comparison of ispaghula husk with lactulose and other laxatives in the treatment of simple constipation. Curr Med Res Opin 1998;14:227-33.

25. Harris KA, Kris-Etherton PM. Effects of whole grains on coronary heart disease risk. Curr Atheroscler Rep 2010;12:368-76.

26. Bruckert E, Rosenbaum D. Lowering LDL-cholesterol through diet: Potential role in the statin era. Curr Opin Lipidol 2011;22:43-8.

27. Hyland CM, Foran JD. Dioctyl sodium sulphosuccinate as a laxative in the elderly. Practitioner 1968;200:698-9.

28. Castle SC, Cantrell M, Israel DS, Samuelson MJ. Constipation prevention: Empiric use of stool softeners questioned. Geriatrics 1991;46:84-6.

29. McRorie JW, Daggy BP, Morel JG, Diersing PS, Miner PB, Robinson M. Psyllium is superior to docusate sodium for treatment of chronic constipation. Aliment Pharmacol Ther 1998;12:491-7.

30. Wesselius-De Casparis A, Braadbaart S, Bergh-Bohlken GE, Mimica M. Treatment of chronic constipation with lactulose syrup: Results of a double-blind study. Gut 1968;9:84-6.

31. Sanders JF. Lactulose syrup assessed in a double-blind study of elderly constipated patients. J Am Geriatr Soc 1978;26:236-9.

32. Freedman MD, Schwartz HJ, Roby R, Fleisher S. Tolerance and efficacy of polyethylene glycol 3350/electrolyte solution versus lactulose in relieving opiate induced constipation: A double-blinded placebo-controlled trial. J Clin Pharmacol 1997;37:904-7.

33. Baldonedo YC, Lugo E, Uzcategui AA, Guelrud M, Skornicki J. [Evaluation and use of polyethylene glycol in constipated patients.] GEN 1991;45:294-7.

34. Corazziari E, Badiali D, Habib FI, et al. Small volume isosmotic polyethylene glycol electrolyte balanced solution (PMF-100) in treatment of chronic nonorganic constipation. Dig Dis Sci 1996;41:1636-42.

35. Corazziari E, Badiali D, Bazzocchi G, et al. Long term efficacy, safety, and tolerabilitity of low daily doses of isosmotic polyethylene glycol electrolyte balanced solution (PMF-100) in the treatment of functional chronic constipation. Gut 2000;46:522-6.

36. Dipalma JA, Cleveland MV, McGowan J, Herrera JL. A randomized, multicenter, placebo-controlled trial of polyethylene glycol laxative for chronic treatment of chronic constipation. Am J Gastroenterol 2007;102:1436-41.

37. DiPalma JA, DeRidder PH, Orlando RC, Kolts BE, Cleveland MB. A randomized, placebo-controlled, multicenter study of the safety and efficacy of a new polyethylene glycol laxative. Am J Gastroenterol 2000;95:446-50.

38. Attar A, Lemann M, Ferguson A, et al. Comparison of a low dose polyethylene glycol electrolyte solution with lactulose for treatment of chronic constipation. Gut 1999;44:226-30.

39. Guest JF, Clegg JP, Helter MT. Cost-effectiveness of macrogol 4000 compared to lactulose in the treatment of chronic functional constipation in the UK. Curr Med Res Opin 2008;24:1841-52.

40. Ford AC, Suares NC. Effect of laxatives and pharmacological therapies in chronic idiopathic constipation: Systematic review and meta-analysis. Gut 2011;60:209-18.

41. Mueller-Lissner S, Kamm MA, Wald A et al. Multicenter, 4-week, double-blind, randomized, placebo-controlled trial of sodium picosulfate in patients with chronic constipation. Am J Gastroenterol 2010;105:897-903.

42. Muller-Lissner SA, Kamm MA, Scarpignato C, Wald A. Myths and misconceptions about chronic constipation. Am J Gastroenterol 2005;100:232-42.

43. Ault A. Zelnorm pulled off the shelf due to possible cardiovascular risk signal. Family Practice News, 2007.

44. Loughlin J, Quinn S, Rivero E, et al. Tegaserod and the risk of cardiovascular ischemic events: An observational cohort study. J Cardiovasc Pharmacol Ther 2010;15:151.

45. Chapman H, Pasternack M. The action of the novel gastrointestinal prokinetic prucalopride on the HERG $\mathrm{K}^{+}$channel and the common T897 polymorph. Eur J Pharmacol 2007;554:98-105.

46. Camilleri M, Kerstens R, Rykx A, Vandeplassche L. A placebo-controlled trial of prucalopride for severe chronic constipation. N Engl J Med 2008;358:2344-54. 
47. Quigley EM, Vandeplassche L, Kerstens R, Ausma J. Clinical trial: The efficacy, impact on quality of life, and safety and tolerability of prucalopride in severe chronic constipation - a 12-week, randomized, double-blind, placebo-controlled study. Aliment Pharmacol Ther 2009;29:315-28.

48. Tack J, van Outryve M, Beyens G, Kerstens R, Vandeplassche L. Prucalopride (Resolor) in the treatment of severe chronic constipation in patients dissatisfied with laxatives. Gut 2009;58:357-65.

49. Tack J. Prucalopride: A new drug for the treatment of chronic constipation. Expert Rev Gastroenterol Hepatol 2009;3:337-43.

50. Muller-Lissner S, Rykx A, Kerstens R, Vandeplassche L. A double-blind, placebo-controlled study of prucalopride in elderly patients with chronic constipation. Neurogastroenterol Motil 2010;22:991-8,e255.

51. Camilleri M, Beyens G, Kerstens R, Robinson P, Vandeplassche L. Safety assessment of prucalopride in elderly patients with constipation: A double-blind, placebo-controlled study. Neurogastroenterol Motil 2009;21:1256-e117.

52. Camilleri M, Van Outryve MJ, Beyens G, Kerstens R, Robinson P, Vandeplassche L. Clinical trial: The efficacy of open-label prucalopride treatment in patients with chronic constipation follow-up of patients from the pivotal studies.

Aliment Pharmacol Ther 2010;32:1113-23.

53. Chmielewska A, Szajewska H. Systematic review of randomised controlled trials: Probiotics for functional constipation. World J Gastroenterol 2010;16:69-75.

54. Mollenbrink M, Bruckschen E. [Treatment of chronic constipation with physiologic Escherichia coli bacteria. Results of a clinical study of the effectiveness and tolerance of microbiological therapy with the E. coli Nissle 1917 strain (Mutaflor)]. Med Klin (Munich). 1994;89:587-93.
55. Yang YX, He M, Hu G, et al. Effect of a fermented milk containing Bifidobacterium lactis DN-173010 on Chinese constipated women. World J Gastroenterol. 2008;14:6237-43.

56. Koebnick C, Wagner I, Leitzmann P, Stern U, Zunft HJ. Probiotic beverage containing Lactobacillus casei Shirota improves gastrointestinal symptoms in patients with chronic constipation. Can J Gastroenterol 2003;17:655-9.

57. Del Piano M, Carmagnola S, Anderloni A, et al. The use of probiotics in healthy volunteers with evacuation disorders and hard stools: A double-blind, randomized, placebo-controlled study. J Clin Gastroenterol 2010;44(Suppl 1):S30-4.

58. Knowles CH, Scott M, Lunniss PJ. Outcome of colectomy for slow transit constipation. Ann Surg 1999;230:627-38.

59. Kamm MA, Hawley PR, Lennard-Jones JE. Outcome of colectomy for severe idiopathic constipation. Gut 1988;29:969-73.

60. Sandlers RS, Drossman DA. Bowel habits in young adults not seeking health care. Dig Dis Sci 1987;32:841-5.

61. Chiarioni G, Whitehead WE, Pezza V, Morelli A, Bassotti G. Biofeedback is superior to laxatives for normal transit constipation due to pelvic floor dyssynergia. Gastroenterology 2006;130:657-64

62. Rao SS, Seaton K, Miller M, et al. Randomized controlled trial of biofeedback, sham feedback, and standard therapy for dyssynergic defecation. Clin Gastroenterol Hepatol 2007;5:331-8.

63. Heymen S, Scarlett Y, Jones K, Ringel Y, Drossman D, Whitehead WE. Randomized, controlled trial shows biofeedback to be superior to alternative treatments for patients with pelvic floor dyssynergia-type constipation. Dis Colon Rectum 2007;50:428-41.

64. Guyatt GH, Oxman AD, Vist GE, et al. GRADE: An emerging consensus on rating quality of evidence and strength of recommendations. BMJ 2008;336:924-6. 


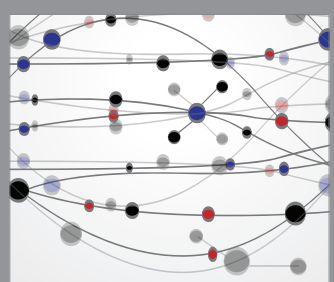

The Scientific World Journal
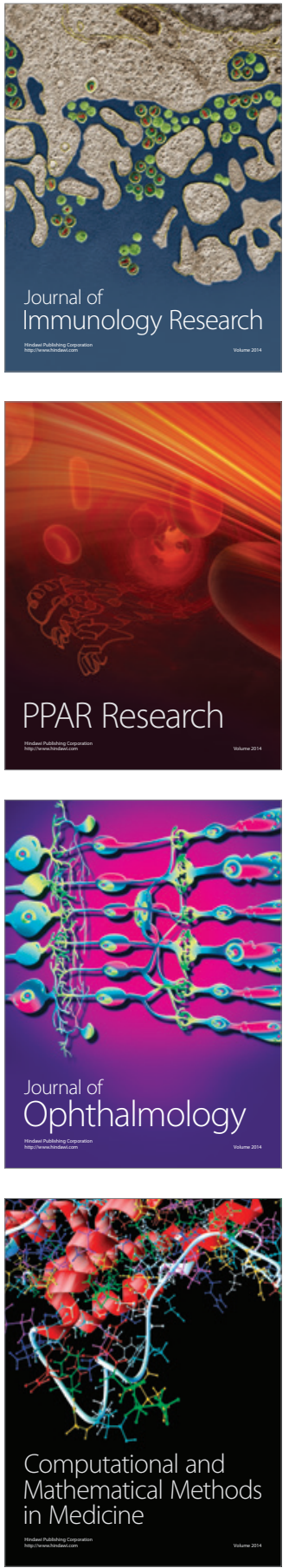

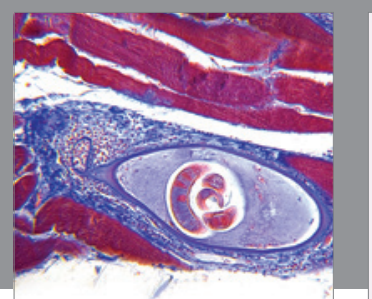

Gastroenterology Research and Practice

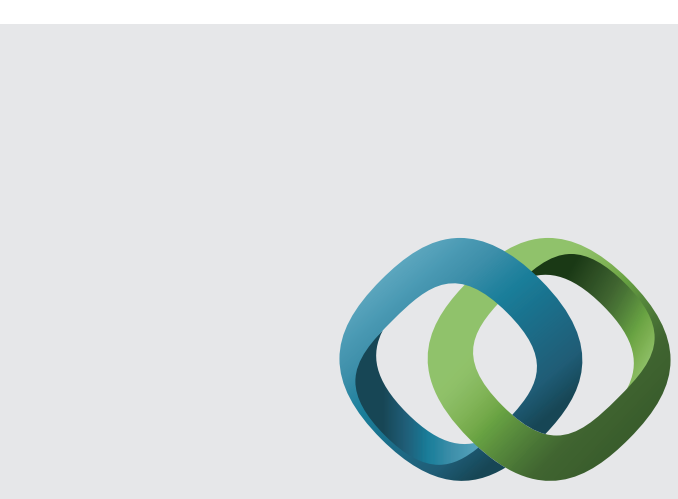

\section{Hindawi}

Submit your manuscripts at

http://www.hindawi.com
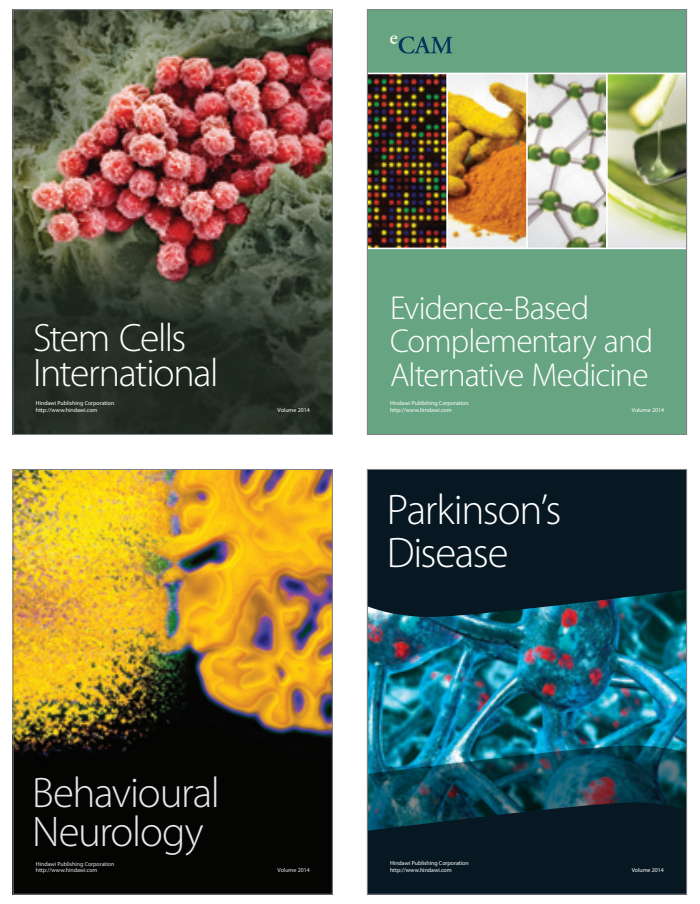
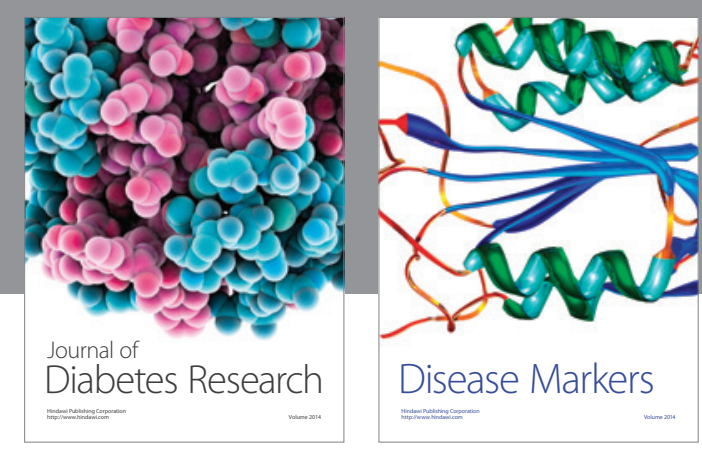

Disease Markers
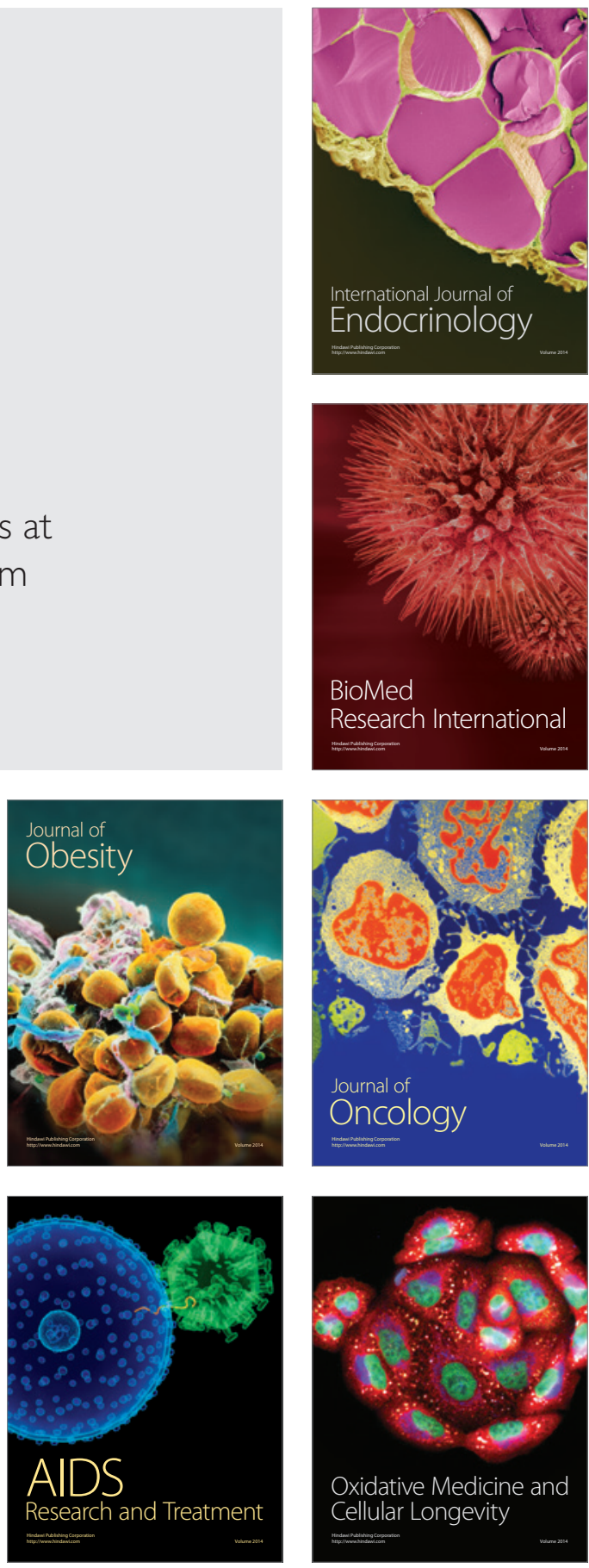